J. CALNAN ET AL.: VENOUS OBSTRUCTION IN THE AETIOLOGY OF LYMPHOEDEMA PRAECOX

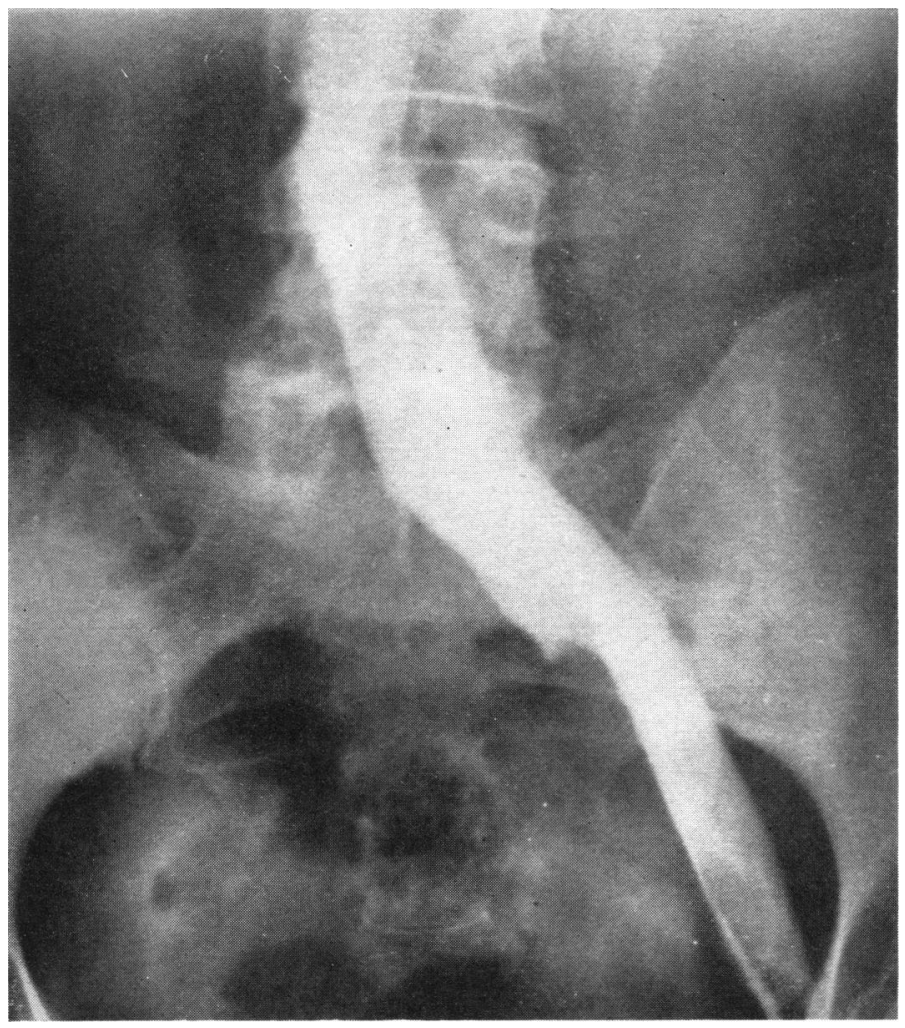

Fig. 1.-Normal venogram. Note the smooth progression of contrast medium from the left common iliac vein into the vena cava, and the absence of collateral vessels.

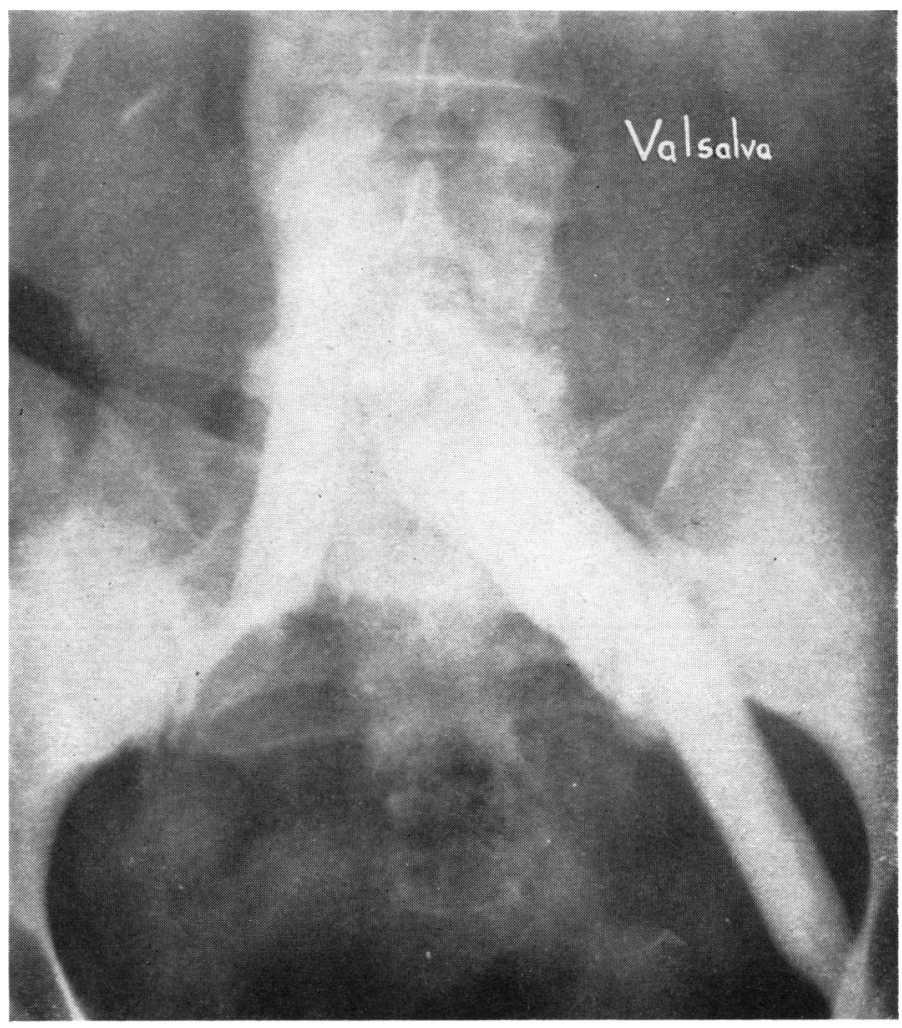

Fig. 2.-Same patient as In Fig. 1 during Valsalva manœuvre. Notice the reflux of contrast medium down the right common iliac vein and the absence of collateral vessels.

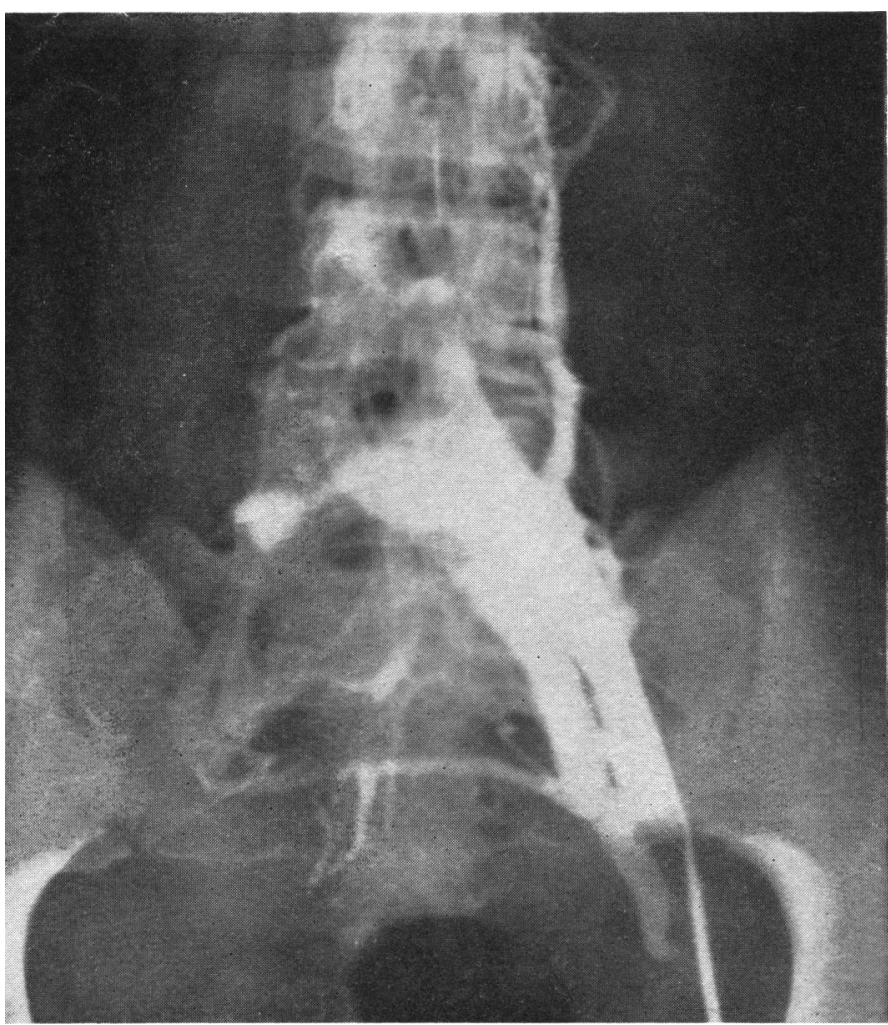

FIG. 3.-Venogram showing obstruction at the site where the left common iliac vein enters the inferior vena cava. Notice collateral vessels crossing the sacrum and by-passing obstruction.

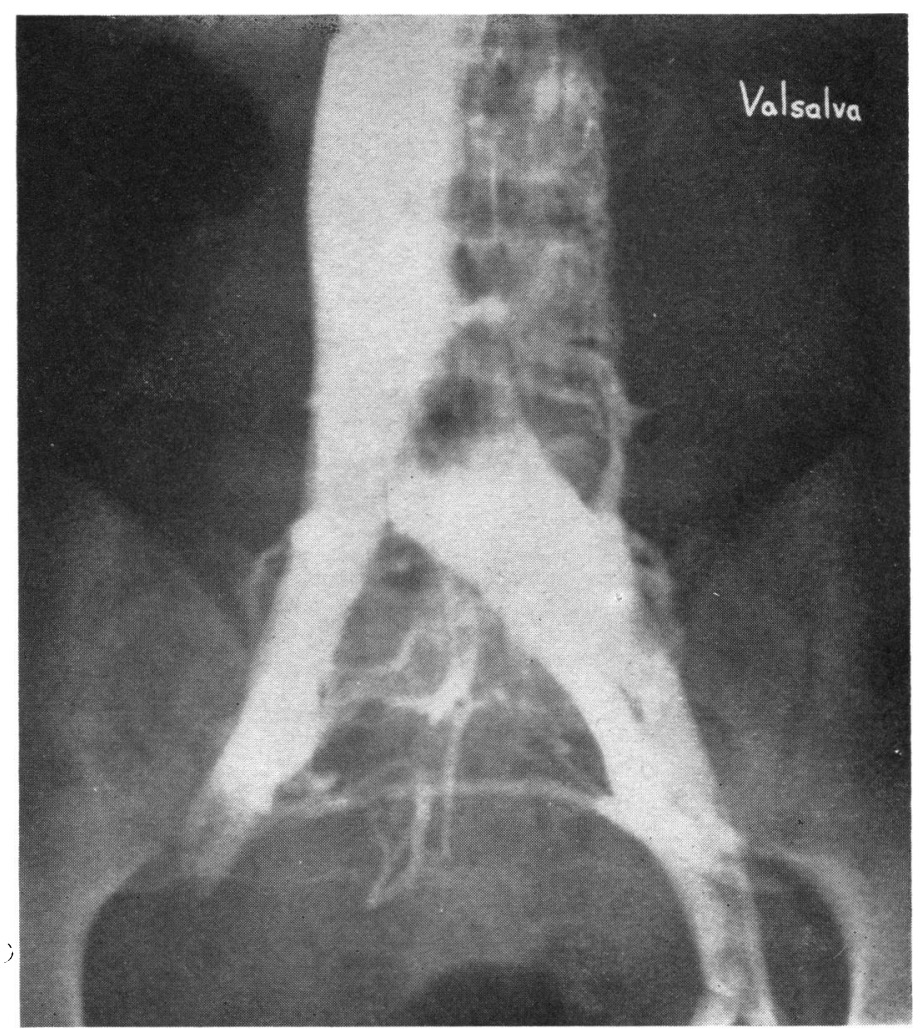

FIG. 4.- Same patient as in Fig. 3 during Valsalva manœuvre. Notice the filling defect at the point where the iliac vein enters the inferior vena cava and marked filling of collateral vessels. The right iliac vein is well outlined. 


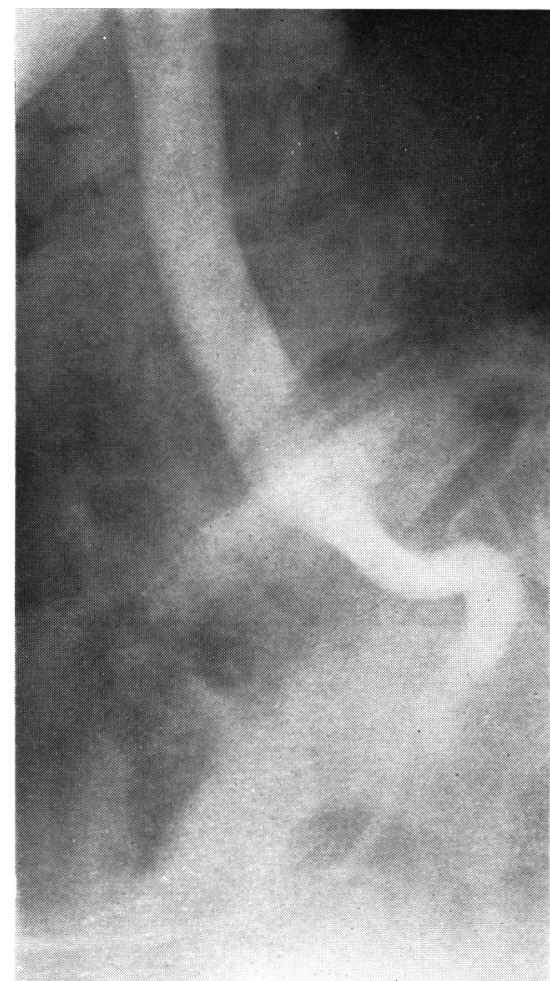

FIG. 5.-Normal lateral venogram. There is no significant narrowing of the junction of the common iliac vein with the inferior ven cava in front of the fourth and fifth lumbar vertebrae.

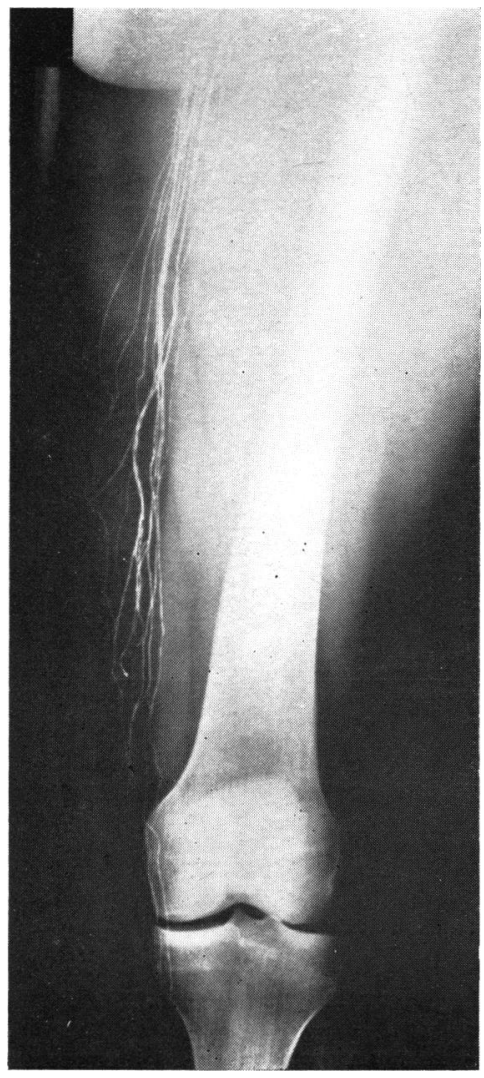

PrG. 8

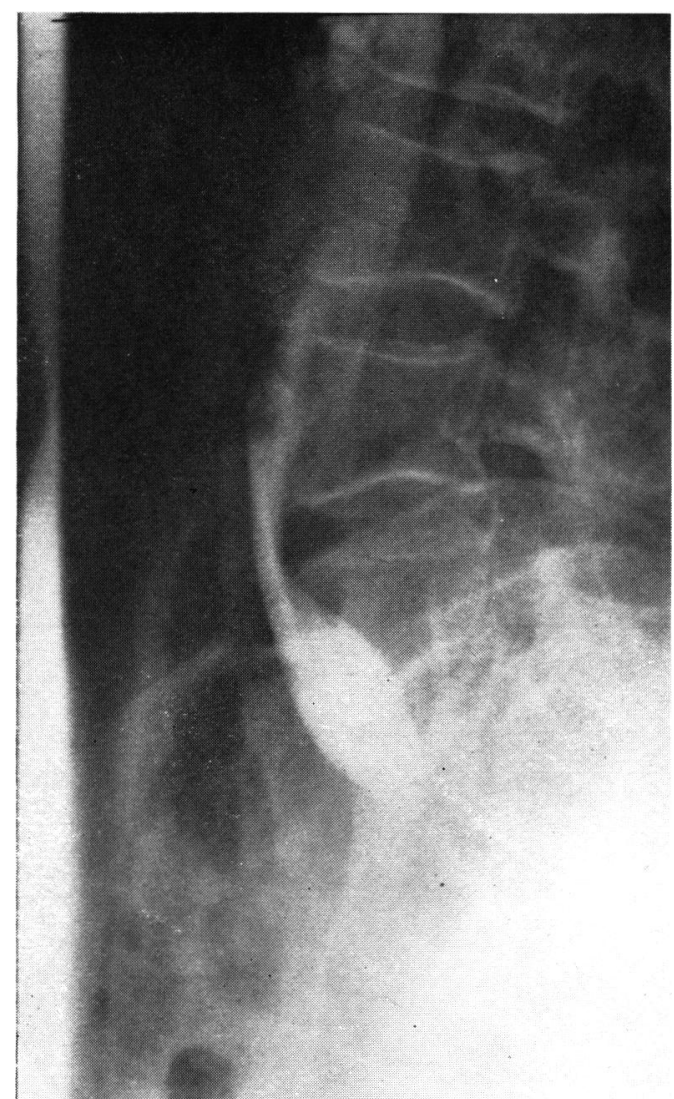

FIG. 6.-Lateral venogram showing marked narrowing of the junction of the common iliac vein with the inferior vena cava in front of the fourth and fifth lumbar vertebrae.

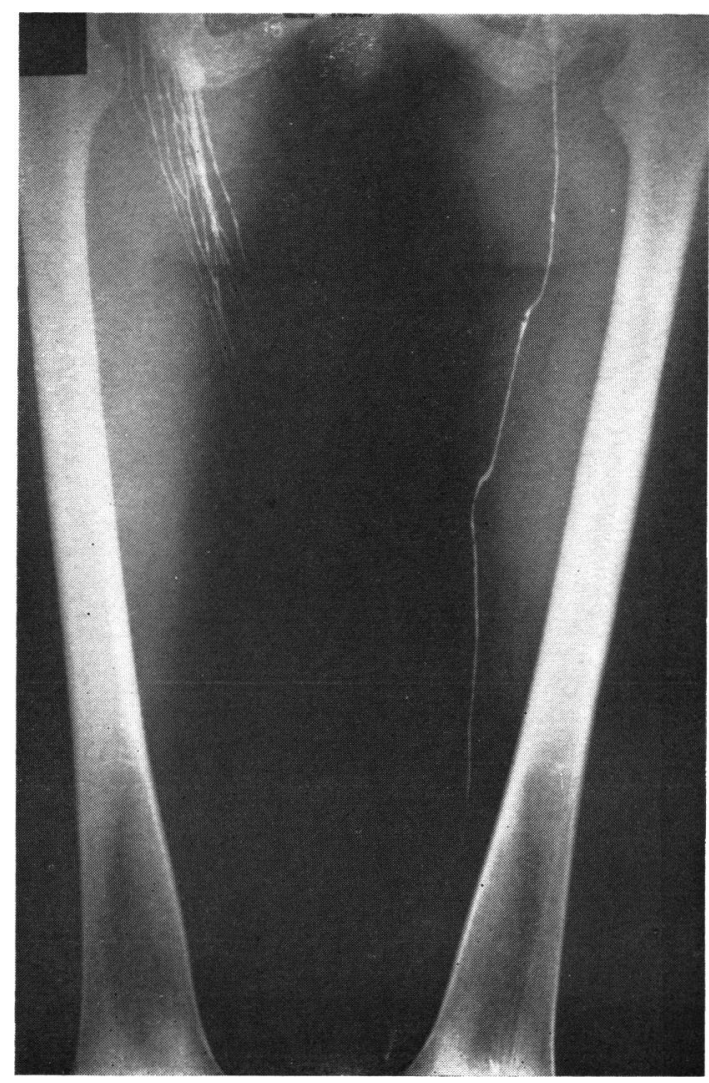

Fig. 9

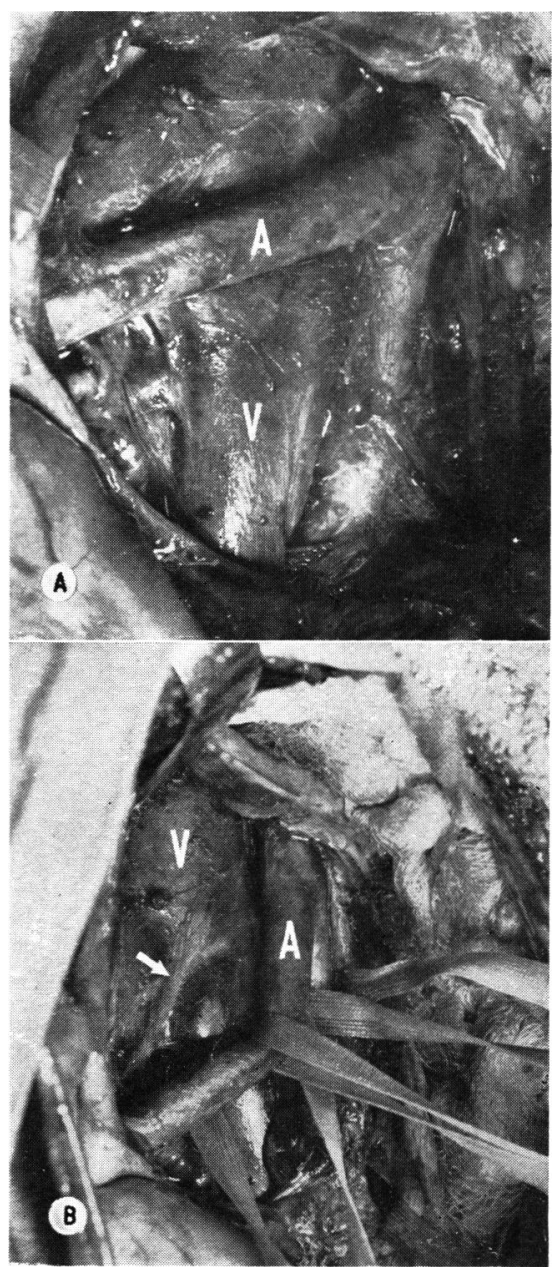

Fig. 7.-Case 17. $A$, The right common iliac artery (A) crossing the left common iliac vein (V) and causing partial obstruction. $B$, The artery has been retracted to show the groove (arrow) it has caused in the vein $(V)$.

FIG. 8.- Normal lymphangiogram of the left leg of a patient with evidence of venous obstruction at the junction of the common iliac vein with the vena cava (thigh only shown).

FIG. 9.-Case 16. Bilateral lymphangiogram. This shows a normal appearance on the right side and only a single lymphatic trunk on the left side. 
nurses, biochemists, and dietitian of the metabolic ward for their invaluable help. The patient and her problem were kindly referred to us by Mr. J. C. Cuthbert.

\section{REFERENCES}

Albright, F., and Reifenstein, E. C. (1948). Parathyroid Glands and Metabolic Bone Disease. Williams and Wilkins, Baltimore.

Bortz, W., Eisenberg, E., Bowers, C. Y., and Pont, M. (1961). Ann. intern. Med., 54, 610.

Burr, J. M., Farrell, J. J., and Hills, A. G. (1959). New Engl. F. Med., 261,1271 . David, N. J., Verner, J. V., and Engel, F. L. (1962). Amer. F. Med., 33,
Dent, C. E. (1962). Brit. med. f., 2, 1495.

- and Harper, C. M. (1962). Lancet, 1, 559.

Hellström, J., and Ivemark, B. I. (1962). Acta chir. scand., Suppl. No. 294.

Hodgkinson, A. (1963). Clin. Sci., 25, 231.

Jackson, C. E., Webster, J. S., Talbert, P. C., and Caylor, H. D. (1961). Ann. intern. Med., 54, 992

Kohn, N. N., and Myerson, R. M. (1961). Ibid., 54, 985.

McGeown, M. G. (1957). Clin. Sci., 16, 297.

- (1962). Lancet, 2, 799.

Thomas, W. C., jun., Connor, T. B., and Morgan, H. G. (1959). New Engl. 7. Med., 260, 591 .

Watson, L. (1963). Postgrad. med. 7., 39, 646.

Watson, L. (1963). Postgrad. med. . $_{2}, 39,646$. . 7. Med. In press.

\title{
Venous Obstruction in the Aetiology of Lymphoedema Praecox
}

\author{
J. S. CALNAN,* M.R.C.P., F.R.C.S. ; S. KOUNTZ,*† M.D. ; B. L. PENTECOST,* M.B., M.R.C.P. \\ J. P. SHILLINGFORD,* M.D., F.R.C.P. ; R. E. STEINER,* M.D., F.F.R.
}

[With Special Plate]

\author{
Brit. med. F., 1964, 2, 221-226
}

Allen (1934) defined lymphoedema as " a swelling of soft tissues which is the result of an increased quantity of lymph" and introduced the term "lymphoedema praecox" to denote primary lymphoedema in early life. He distinguished this from the familial congenital type of Nonne (1891) and Milroy (1892). The praecox form constituted 93 of Allen's 146 cases of primary lymphoedema. Kinmonth, Taylor, Tracey, and Marsh (1957) restricted the adjective "praecox" to those patients in whom the initial oedema appeared before the age of 35 years, and their series of 107 cases of primary lymphoedema contained 83 such patients.

The onset of swelling occurs spontaneously and often affects one leg only, as in $70 \%$ of Allen's cases. The oedema is more pronounced during long periods of activity, during menstruation, and in warm weather. There is usually progressive involvement of the entire limb. Early in the disease the oedema is soft, but later, as the protein content of the fluid increases, there is proliferation of fibrous tissue and the swollen limb will no longer pit on digital pressure. Although the course is often painless, attacks of lymphangitis may occur, and it is occasionally difficult to decide whether the initial incident was oedema or an inflammation, but a careful history usually allows the distinction to be made (Smith, Spittell, and Schirger, 1963).

Allen pointed out that lymphoedema praecox often begins during puberty and adolescence, and that it is much commoner in women. Among Allen's 93 patients with this form of lymphoedema, $65 \%$ were affected between the ages of 9 and 25 years and $87 \%$ were women. Kinmonth et al. (1957) and Schirger, Harrison, and Janes (1962) found a similar sex-andage distribution in their large series. Adequate explanation for these two constant and striking features has never been presented. Minor trauma is frequently offered as a precipitating factor in lymphoedema, but there is no reason for this to occur more often either during adolescence or in the female sex. The answer to this problem must involve the basic nature of the disorder. The work of Kinmonth (1952) and Kinmonth, Taylor, and Harper (1955) on lymphangiography resulted in a description of the lymphatic vessels in primary lymphoedema

\footnotetext{
- From the Departments of Surgery and Radiology and the M.R.C Cardiovascular Research Group, Postgraduate Medical School, and Hammersmith Hospital, London.

+ In receipt of Grant No. HE 5603-01 from the National Institutes of
Health, U.S.A.
}

in 1957. Hypoplastic vessels occurred in $55 \%$ of patients, aplastic in $14 \%$, and broad, tortuous, or varicose lymphatics in $24 \%$; the phenomenon of dermal backflow was found as the only abnormal radiological feature in $6 \%$ of the series but was present in $22 \%$ of all patients in the group. This latter radiological appearance resulted from filling of the dermal lymph plexus distal to areas of imperfect lymph drainage. The importance of lymphatic vessel abnormality is clear, and these authors considered that their data supported the suggestion of Allen, Barker, and Hines (1946): "That it is possible that the entire explanation rests on a congenital under-development of the lymphatics."

Little attention has been paid to the venous drainage in these extensive series of patients, although Aird (1950) and Boyd (1950) have drawn attention to the frequent occurrence of venous abnormalities among patients with clinical lymphoedema. It was with this in view and by the application of modern radiological and haemodynamic techniques that the followiug study was undertaken.

\section{Materials and Methods}

Twenty-three consecutive patients with lymphoedema praecox were studied. In all of them the oedema had begun before the age of 30 years. The details of age and sex together with other data are presented in the Table. It can be seen that 20 of the 23 patients are women.

In each patient the venous drainage from the limb was investigated by percutaneous femoral venography and venous flow and pressure measurements in the common iliac veins. Lymphangiography was successfully performed in 10 cases.

\section{Venous-flow Studies}

The continuous-injection-indicator-dilution technique described by Shillingford, Bruce, and Gabe (1962) and subsequently used by Pentecost, Irving, and Shillingford (1963) in the inferior vena cava was used to measure venous flow. A specially adapted No. 9 double-lumen cardiac catheter with a stainless-steel spray-tip was inserted into a median vein in the antecubital fossa under local anaesthesia and advanced under 
direct fluoroscopic control via the right atrium into the inferior vena cava. The venous flow was then measured in the inferior vern cava and in the common iliac veins. Where it proved impossible to enter both common iliac veins it was possible to calculate the flow from the uncatheterized side by subtracting the measured common iliac flow from that in the lower inferior vena cava. In two studies each patient's sacro-lumbar region was extended by placing a flat pillow 2 in. $(5 \mathrm{~cm}$.) deep beneath the buttocks, and the change in venous flow accompanying this manœuvre was measured.

\section{Radiological Technique of Venography}

All patients were examined under local anaesthesia. The left femoral vein was catheterized just below the inguinal ligament by the percutaneous Seldinger technique. Before the Seldincer needle was introduced into the femoral vein the patient was asked to perform a Valsalva manœuvre to distend the vein and make the percutaneous puncture easier. A 205 Seldinger needle was used in all patients and a grey Kifa catheter was introduced into the vein over a standard 205 guide wire. The cacheter had previously been pre-shaped by slightly curving its free end so that the inferior vena cava and right common iliac vein could be catheterized from the left side more easily. Once the catheter was adequately placed into the femoral vein it was advanced, under fluoroscopic control, with the aid of an image amplifier and television unit, into the common iliac vein, into the inferior vena cava, and occasionally across into the right iliac vein. During the procedure the catheter was irrigated with heparinized saline.

If there was any resistance to the progress of the catheter a very small test injection of $45 \%$ Hypaque (sodium diatrizoate) was made to demonstrate any abnormality in the anatomy in the vicinity of the tip of the catheter and just beyond. In all patients there was no difficulty in overcoming any minor obstruction by gentle rotation of the catheter, repositioning it, and further advancing it under direct screen control. Once the catheter had been introduced into the inferior vena cava it was connected to a strain-gauze manometer and pressure recordings were obtained in the inferior vena cava; a withdrawal tracing was then taken from the inferior vena cava to the left common iliac vein, into the external iliac vein and femoral vein. In a number of patients it was possible to catheterize the right common iliac vein from the left side, and pressure recordings were then obtained in the right iliac vein and subsequently withdrawal tracings were obtained from the right iliac vein, the inferior vena cava, and the left common iliac vein. Once the pressure records were obtained the catheter was finally placed in the external iliac vein and the patient positioned for the angiographic procedure.

\section{Radiographic Technique}

With few exceptions, the patients were examined on a cut film 14 by 14 in. ( 35.5 by $35.5 \mathrm{~cm}$.) Schonander serial changer, and films taken at the rate of 2 per second for eight seconds, to demonstrate the circulation in the iliac vein and the inferior vena cava. In a number of patients the examination was repeated with the patient performing a Valsalva manœuvre to demonstrate venous reflux, to obtain filling of collateral vessels, and to distend the venous system to a maximum. Injection of contrast medium was carried out as rapidly as possible; $30 \mathrm{ml}$. of $65 \%$ Hypaque was used, and this amount was delivered by hand-injection in about two seconds. The area radiographed by the serial examination extended from the lower pelvis, just below the symphysis to the L 1-2 level. In a smaller number of patients the standard Schonander serial film changer was not used, but instead a manually operated serial device, operating at a slower rate but covering the same area, was employed.

After the injection of contrast medium into the iliac vein, lateral films of the lumbo-sacral region were taken, using an $x$-ray beam. This was done to demonstrate the ileo-caval junction, at the point where the left iliac vein is crossed by the right iliac artery in front. The lateral films were obtained, making two separate injections of $20 \mathrm{ml}$. of $65 \%$ Hypaque: in the first instance with the patient lying flat on the back with legs extended, and in the second instance with the patient's hips and knees flexed and the back flexed forward into a semisitting position. These examinations were carried out to evaluate the extent of venous compression between the sacral promontory and lumbar lordosis from behind, and the compression from the crossing iliac artery from the front, both in extension and in partial flexion. At the end of this procedure the catheter was withdrawn and haemostasis achieved by short temporary compression of the femoral vein over the puncture site.

\section{Investigations of the Lumbo-sacral Angle and Lumbar Lordosis}

To assess the angle of the lumbo-sacral joint at the level of L 4-5 a group of patients and a control group were radiographed in the lateral erect position with the $x$-ray beam centred on the lumbo-sacral region and the angle between L 4 and 5 and $\mathrm{L} 5$ and $S 1$ measured after the methods of Schmorl and Junghanns (1959).

\begin{tabular}{|c|c|c|c|c|c|c|c|c|c|}
\hline \multirow{2}{*}{$\begin{array}{l}\text { Case } \\
\text { No. }\end{array}$} & \multirow{2}{*}{$\begin{array}{c}\text { Leg } \\
\text { Involved }\end{array}$} & \multirow{2}{*}{$\begin{array}{l}\text { Sex } \\
\text { and } \\
\text { Age }\end{array}$} & \multirow{2}{*}{$\begin{array}{l}\text { Age } \\
\text { at } \\
\text { Onset }\end{array}$} & \multirow{2}{*}{$\begin{array}{l}\text { Radiological } \\
\text { Evidence of } \\
\text { Venous } \\
\text { Obstruction }\end{array}$} & \multicolumn{2}{|c|}{$\begin{array}{l}\text { Venous Blood Flow } \\
\text { ml./min. }\end{array}$} & \multirow{2}{*}{$\begin{array}{c}\text { Pressure } \\
\text { Gradient Across } \\
\text { Obstruction } \\
(\mathrm{mm} / \mathrm{Hg})\end{array}$} & \multirow{2}{*}{$\begin{array}{c}\text { Direct } \\
\text { Inspection } \\
\text { Lymphangiography }\end{array}$} & \multirow{2}{*}{$\begin{array}{l}\text { Radiological } \\
\text { Appearances }\end{array}$} \\
\hline & & & & & R.C.I.V. & L.C.I.V. & & & \\
\hline $\begin{aligned} 1 \\
2 \\
3 \\
4 \\
5 \\
6 \\
7 \\
8 \\
9 \\
10 \\
11 \\
12 \\
13 \\
14 \\
15 \\
16 \\
17 \\
18 \\
19 \\
20 \\
21\end{aligned}$ & $\begin{array}{l}\text { Left } \\
\text { Left } \\
\text { Left } \\
\text { Left } \\
\text { Both } \\
\text { Left } \\
\text { Left } \\
\text { Left } \\
\text { Left } \\
\text { Right } \\
\text { Right } \\
\text { Both } \\
\text { Left } \\
\text { Right } \\
\text { Left } \\
\text { Left } \\
\text { Left } \\
\text { Left } \\
\text { Left } \\
\text { Left } \\
\text { Left }\end{array}$ & $\begin{array}{rl}\mathrm{F} & 17 \\
\mathrm{~F} & 23 \\
\mathrm{~F} & 22 \\
\mathrm{~F} & 15 \\
\mathrm{M} & 47 \\
\mathrm{~F} & 45 \\
\mathrm{~F} & 15 \\
\mathrm{~F} & 20 \\
\mathrm{~F} & 23 \\
\mathrm{~F} & 37 \\
\mathrm{~F} & 38 \\
\mathrm{~F} & 28 \\
\mathrm{~F} & 32 \\
\mathrm{~F} & 35 \\
\mathrm{M} & 12 \\
\mathrm{~F} & 18 \\
\mathrm{~F} & 20 \\
\mathrm{~F} & 28 \\
\mathrm{~F} & 38 \\
\mathrm{M} & 40 \\
\mathrm{~F} & 22\end{array}$ & $\begin{array}{r}16 \\
20 \\
15 \\
9 \\
15 \\
15 \\
11 \\
13 \\
20 \\
20 \\
18 \\
10 \\
15 \\
10 \\
10 \\
15 \\
18 \\
18 \\
8 \\
20 \\
17\end{array}$ & $\begin{array}{l}\text { Absent } \\
\text { Absent } \\
\text { Present } \\
\text { Present } \\
\text { Absent } \\
\text { Absent } \\
\text { Absent } \\
\text { Present } \\
\text { Absent } \\
\text { Absent } \\
\text { Present on extension } \\
\text { Present } \\
\text { Absent } \\
\text { Present } \\
\text { Present } \\
\text { Present } \\
\text { Present on extension only } \\
\text { Present } \\
\text { Absent } \\
\text { Absent }\end{array}$ & $\begin{array}{r}434 \\
460 \\
500 \\
922 \\
986 \\
809 \\
601 \\
500 \\
670 \\
810 \\
631 \\
680 \\
1,059 \\
500 \\
550 \\
1,520 \\
900 \\
440 \\
775 \\
500 \\
400\end{array}$ & $\begin{array}{r}347 \\
510 \\
60 \\
230 \\
850 \\
800 \\
579 \\
460 \\
0 \\
700 \\
519 \\
584 \\
305 \\
852 \\
700 \\
0 \\
0 \\
540 \\
0 \\
470 \\
360\end{array}$ & $\begin{array}{l}0 \\
0 \\
\overline{5} \\
0 \\
0 \\
0 \\
\overline{-} \\
0 \\
0 \\
5 \text { on extension } \\
8 \\
= \\
\bar{Z} \\
\frac{5}{1} \\
0 \\
0\end{array}$ & $\begin{array}{l}\text { Hypoplastic } \\
\text { Hypoplastic } \\
\overline{\text { Hypoplastic }} \\
\overline{\bar{H}} \\
\overline{\text { Hypoplastic }} \\
\text { Nopoplastic } \\
\overline{\text { Tormal }} \\
\bar{E} \\
\overline{\bar{N}} \\
\overline{\text { Normal }} \\
\text { Normal }\end{array}$ & $\begin{array}{l}\text { Failed } \\
\text { Failed } \\
\text { Hypoplastic } \\
\text { Failed } \\
\text { Hypoplastic } \\
\text { Failed } \\
\text { Failed } \\
\text { Normal } \\
\text { Hypoplastic } \\
\text { Failed } \\
\text { L.hypoplastic, R. normal } \\
\text { Normal } \\
\text { Normal } \\
\text { Normal } \\
\text { Normal }\end{array}$ \\
\hline $\begin{array}{l}22 \\
23\end{array}$ & $\begin{array}{l}\text { Both } \\
\text { Left }\end{array}$ & $\begin{array}{ll}\mathrm{F} & 20 \\
\mathrm{~F} & 32\end{array}$ & $\begin{array}{l}16 \\
20\end{array}$ & $\begin{array}{l}\text { Present on extension } \\
\text { Absent }\end{array}$ & $\begin{array}{l}605 \\
910\end{array}$ & $\begin{array}{l}645 \\
683\end{array}$ & $\frac{(8 \text { on extension) }}{0}$ & $\overline{\text { Hypoplastic }}$ & $\begin{array}{l}\text { Hypoplastic } \\
\text { Failed }\end{array}$ \\
\hline
\end{tabular}




\section{Lymphangiography}

The technique used at the beginning of this investigation was that described by Kinmonth (1954). Patent blue violet (10\%) injected into the toe webs outlined the lymphatic trunk on the dorsum of the foot, which was then cannulated by a No. 30 needle. Hypaque $45 \%$ injected by hand was the $x$-ray contrast medium.

The method was later modified (to be published). A No. 27 Solila dental needle is now used to cannulate the lymph trunk, and an oily medium (Neo-hydriol or Lipiodol-Ultra) instilled by a constant-injection machine gives better definition of lymph trunks and nodes (Gough, Guiney, and Kinmonth, 1963).

\section{Results}

\section{Film Interpretation of Venographic Studies}

In the group of patients without venous obstruction at the ileo-caval junction a smooth transition zone from one vessel to the other was seen without significant distortion or compression of the vessel wall (Special Plate, Fig. 1). There was, however, distinct widening of the iliac vein just proximal to its junction with the vena cava. The density of contrast in the iliac vein and vena cava was more or less uniform in the transition zone and collateral vessels did not fill. When the Valsalva manœuvre was carried out filling of the collaterals took place, the venous pathway appeared distended, and occasionally there was considerable reflux into the femoral vein and even into the right iliac vein (Special Plate, Fig. 2). These appearances were in distinct contrast to those seen in the group of patients with venous obstruction. In these patients the transition zones from iliac vein to vena cava was not homogeneous, and a distinct band of translucency was visible at the ileo-caval junction (Special Plate, Fig. 3); this varied in width and density with the degree of obstruction and compression by the crossing right iliac artery. In addition to the compressing band and associated change in contrast density, broadening of the iliac vein at the point of compression and just proximal to it was very much more marked than in the normal group of patients. The collateral vessels often filled even without the Valsalva manœuvre. Occasionally collateral veins seemed to extend across the sacrum, filling the opposite iliac vein, or extended up into the abdomen, filling lumbar collateral veins (Special Plate, Fig. 4).

\section{Interpretation of Lateral Projection Film with Horizontal Beam}

In patients without venous obstruction the ileo-caval anastomosis appeared to be quite smooth, with only slight compression of the iliac vein and cava from behind at a point where these vessels overlie the lumbo-sacral junction and L 4-5 lordosis (Special Plate, Fig. 5). The veins were slightly narrowed in the antero-posterior diameter compared with the A.P. diameter of the veins just above and below. This slight compression was abolished once the patient flexed the hips, knees, and spine. In patients with venous obstruction the ileocaval junction was very markedly compressed and the A.P. diameter of the veins very narrow indeed (Special Plate, Fig. 6). On the films taken in flexion the venous compression was slightly decreased but in no case completely abolished.

\section{Interpretation of Flow and Pressure Studies}

Under normal resting conditions both common iliac veins contribute from 400 to $800 \mathrm{ml}$. of blood per minute to the flow in the inferior vena cava, and the amount from both veins is approximately equal. In the presence of venous obstruction the flow from the obstructed side is much reduced and in some cases appears to be almost nil. Interference to venous return was inferred empirically when the venous flow in one iliac vein was less than $30 \%$ of the other. Normally, no pressure gradient is detectable between the common iliac veins and the inferior vena cava.

Among the 23 patients studied thers was radiological evidence of venous obstruction as described above in 11 . It can be seen from the Table that all these patients had lymphoedema either involving the left leg alone or bilateral lymphoedema which had started and remained more marked on the left. In each case the site of obstruction was where the left common iliac vein joins its fellow to form the inferior vena cava. In four of the 11 cases with an obstruction this was passed by the femoral vein catheter and a pressure gradient recorded. This was recorded with the patient horizontal at rest, and varied between 5 and $10 \mathrm{~mm}$. $\mathrm{Hg}$. In one patient in whom there was no pressure gradient between the vena cava and left common iliac vein, one of $8 \mathrm{~mm}$. Hg was induced by slight extension of the spine in the lumbo-sacral region. Among these 11 patients there was evidence of venous obstruction from flow studies in seven, each of whom showed a complete radiological block of the left common iliac vein. Among the remaining four patients with positive radiological findings but no diminished blood flow from the affected leg, the obstruction did not appear complete radiologically in three, but was made so by slight dorsiflexion at the lumbo-sacral joint. There were no patients in whom flow studies suggested obstruction in the absence of radiological abnormalities. The 11 patients with radiological evidence of venous obstruction include nine in whom the oedema was entirely left-sided and two in whom the oedema was bilateral but predominantly left-sided.

\section{Interpretation of Lymphangiograms}

Among the 11 with venous obstruction it was possible to perform successful lymphangiography in only six; three were normal (Special Plate, Fig. 8) and three showed hypoplastic lymphatics on the affected side. In a further four of these patients without venous obstruction lymphangiography was successful ; two showed hypoplastic lymphatics and two normal lymphatic channels; one of the latter was the young woman (Case 21) in whom a pressure gradient of $8 \mathrm{~mm}$. $\mathrm{Hg}$ was produced at the usual site by slight extension of the lumbo-sacral region; radiological studies were not repeated in this position. In a further six cases lymphangiography was unsuccessful because the dye, vital blue $\mathrm{V}$, either failed to reveal any lymphatic vessels or failed to show any vessel sufficiently large to cannulate. Two of these were patients with evidence of venous obstruction.

Radiological assessment of the lumbo-sacral angle among our patients at the L 4-5 and L 5-S 1 sites showed no significant difference from a control group of women of the same age and were within the normal range for this movement published by Schmorl and Junghanns (1959).

\section{Case 17}

\section{Clinical Examples}

A 20-year-old girl had noticed increasing swelling of the left lower leg after a cartilage operation two years previously. The left leg had always been a little swollen, but it had become much worse after the operation, and had never returned to normal even with elastic bandages and a long period of rest in bed. There had been no illness suggestive of thrombophlebitis or lymphangitis. Lymphangiography had been attempted unsuccessfully in September 1961, and she was then referred to Hammersmith Hospital.

The venogram showed an obstruction to be present where the left common iliac vein enters the inferior vena cava. Injected dye 
failed to enter the right common iliac vein from the left until the Valsalva manœuvre was performed, when the dye appeared to enter the latter vessel via pelvic collateral vessels. The venous flow catheter wedged firmly at the junction of the left common iliac vein and vena cava and there appeared to be no flow in this region. Lymphangiography demonstrated normal lymph trunks and nodes.

Laparotomy was performed and the posterior parietal peritoneum was incised as an inverted $\mathrm{V}$. disclose the right common iliac artery, which was cleared above to the aorta and below to its division into external and internal iliac arteries. The posteriorly situated left common iliac vein shcwed a fusiform dilatation distal to where the artery crossed it. On lifting the right common iliac artery off the left vein, a grooved depression in the vein which accommodated the artery was observed (Special Plate, Fig. 7). These surgical findings confirmed the radiological appearances on venography. The right common iliac artery was divided distally and rerouted behind the left vein and resutured.

Post-operatively a substantial improvement was noted in the oedematous condition of the leg but recently the oedema has returned. Studies of the venous anatomy and function have not yet been repeated.

\section{Case 3}

A woman aged 22 first noticed a swelling of the left leg when she was 15 years old. The leg had increased in size rapidly over the first 12 months but subsequently more slowly. There had been no obvious precipitating cause for the oedema and no attacks of lymphangitis or thrombophlebitis. At the age of 19 the oedema had become severe enough to warrant an operation to remove swollen subcutaneous tissue below the knee; but this was unsuccessful, as was a more extensive Kondoleon operation performed the following year.

On examination at the age of 22 the entire left limb was markedly swollen. The oedema could not be pitted, although this had been possible one year earlier. There was no other evidence of organic disease.

When venous-flow studies were don: the left common iliac vein could not be entered. The flow in the low $\mathrm{r}$ inferior vena cava was $560 \mathrm{ml} . / \mathrm{min}$. and the flow in the right ccrmon iliac vein was 500 $\mathrm{ml} . / \mathrm{min}$. Similar estimations resulted from severdi studies. The blood-flow from the left common iliac vein was deduced to be of the order of $60 \mathrm{ml} . / \mathrm{min}$. A venogram both from the inferior vena cava and from below the junction of the vena cava and the left common iliac vein revealed an apparent obstruction at the same site as in Case 17. Lymphangiography failed, but the vessels found on dissection in the left foot, outlined by vital blue V, were few in number and hypoplastic in appearance.

At operation the right common iliac artery crossed the left common iliac vein, as described in Case 17, and the appearances of the latter vessel were similar. An attempt was made to remove the obstruction by elevating the artery on fatty cutaneous pylons. The operation was completed without incident, but there has been no lessening of the oedematous state.

\section{Case 16}

This girl aged 18, had been born with constricting bands around the left thigh, calf, and foot. During the previous few years the left lower leg had become increasingly oedematous. Surgery to the constricting bands had improved the appearance of the leg but had done nothing to relieve the oedema.

Venography showed similar appearances of obstruction of the left common iliac vein to those described in the preceding two cases. Venous-flow studies showed a right common iliac flow of 1,520 $\mathrm{ml} . / \mathrm{min}$. and no flow from the left common iliac vein. It was not possible to pass a catheter from the left common iliac vein to the vena cava either from above or from below in order to measure a pressure gradient.

Lymphangiography demonstrated radiologically hypoplastic lymph vessels in the left leg and normal vessels on the right side (Special Plate, Fig. 9).

No surgical correction has been attempted.

\section{Discussion}

It is necessary to consider first the nature of the lesion demonstrated and subsequently to discuss the manner in which venous obstruction would influence the onset of lymphoedema.

The left common iliac vein is crossed by the right common iliac artery just before the former vessel enters the inferior vena cava. At the crossing-point both vessels lie anterior to the body of the fourth lumbar vertebra. The retroperitoneal bloodvessels follow closely the contour of the pelvis, and their course will be influenced by any change that may occur in the pelvic anatomy. During the process of sexual maturity in the female the sacrum becomes turned back to a greater extent than in the male; this would tend to increase the lumbo-sacral angle, but an increase in lumbar lordosis counteracts such a change (see Diagram) (Fraser, 1940). There is no demonstrable difference in the lumbo-sacral angle between the two sexes (Schmorl and Junghanns, 1959). It can be seen that there will be a greater tendency for the vein to be compressed between artery and bone in the mature female pelvis. We have not demonstrated any abnormal degree of sacral displacement or increase in lumbosacral angle among patients in whom there was evidence of venous obstruction. It is possible that such a state of venous obstruction may exist in non-oedematous people, but we have not noticed any abnormality during either flow or radiological studies on this region in patients investigated for other reasons.

There are further points of evidence in favour of venous obstruction from this cause. Increasing the extension of the lumbo-sacral spine in two patients resulted in a reduction of blood-flow in the lower inferior vena cava by $50 \%$. We have shown that flexion of the lumbo-sacral spine will improve the

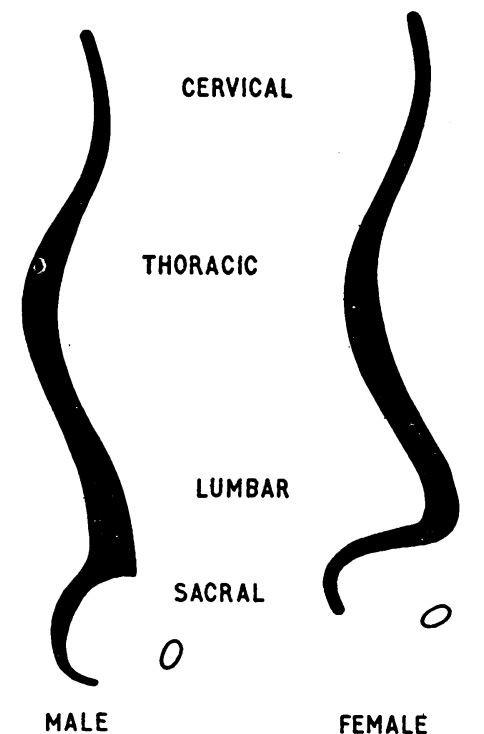

Adult male and female vertebral outines in lateral view (redrawn after Fraser, 1940).

flow of radio-opaque medium from the left common iliac vein to inferior vena cava, and it is possible in some patients to produce a pressure gradient from the left common iliac vein to inferior vena cava by extension of the lumbo-sacral spine, which can then be abolished by flexion. It is to be noted that these studies have been performed with the patient supine, but the lumbar lordosis and pelvic tilt is increased by standing, as is the severity of lymphoedema in its early stages. Some of the patients of Kinmonth et al. (1957) dated their lymphoedema from a normal pregnancy, which accentuates these postural changes. The appearances of the blood-vessels at operation support this hypothesis. The right common iliac artery had clearly grooved and compressed the vein, and the abnormally flattened and distended vein rapidly resumed a more tubular and uniform appearance after retraction of the artery. 
An alternative explanation of the findings, both radiological and haemodynamic, could be the presence of an intravascular obstructive lesion. McMurrich (1908) described the presence of such a lession in one common iliac vein in 35 out of 107 routine necropsies. The lesion was a fusion of anterior and posterior walls of the vein, usually columnar but occasionally marginal ; in 32 of the 35 cases the lesion was situated on the left side only. McMurrich thought these lesions were congenital and represented imperfect development of the communicating branch joining the inferior vena cava to the left iliac vein. Ehrich and Krumbhaar (1943) found a similar incidence of adhesions (33.8\%) among a larger series of routine necropsies. They noted that the incidence of adhesions increased with age and concluded that they were acquired, possibly as a result of trauma from the overlying artery.

We are unable to say whether or not such lesions existed in some of our patients, but no adhesions were apparent in those veins inspected at operation, and the variability of block with posture suggests that a permanent obstruction was not present. However, both external compression and internal adhesions could exist together, so that any surgical therapy, short of vessel exploration, might be ineffcctive. We think that the lesion is most likely that of external compression of the vein by the right common iliac artery.

Now it is unlikely that lymphoedema can be due to venous obstruction alone, because the inferior vena cava can often be tied without subsequent chronic oedema (Schauble, Stickel, and Anlyan, 1962). However, chronic oedema does occur on occasion. Zimmermann and de Takats (1931) failed to produce chronic oedema by the ligation of proximal major limb vessels in dogs, but we agree with Peck (1957) that this experimental work in dogs cannot be readily applied to man because of their different postures.

There are, however, several ways in which venous obstruction could impair the efficient working of the lymphatic system : by increasing the rate of extravascular fluid formation, by disturbing the reabsorption of lymph via lymphatics, and, finally, lymphatic vessels might suffer permanent damage by direct involvement in an inflammatory process like thrombophlebitis or because of prolonged distension and subsequent varicosity formation or fibrosis.

Starling (1894) indicated that an increased hydrostatic pressure at the venous end of a capillary system would result in formation of increased tissue fluid. White, Field, and Drinker (1933) placed a cuff around the limb of a dog and showed that the lymph flow increased progressively as the venous pressure was raised. McMaster (1937a, 1937b) found that following venous obstruction there was a period of increased lymph flow, which he demonstrated by visible "streamer" formation after the injection of minute quantities $(0.02 \mathrm{ml}$.) of Pontamine blue intradermally. He also showed that superficial lymphatics of the leg were dilated in congestive cardiac failure with peripheral oedema, and that the flow of the lymph was much reduced but improved greatly with reduction of venous pressure following diuresis. In contrast, he found that the lymph flow in the dilated vessels of chronic renal oedema was increased at rest. The most obvious difference between the two groups was the high venous pressure of the former. However, even with the patient horizontal, the streamer formation in the arms still exceeded that in the legs, but this manœuvre could not be expected to correct immediately the effects of a chronically raised venous pressure.

Such a dilatation as McMaster demonstrated is apparently passive and occurs as a result of stretching the reticular fibres attached to lymphatic vessel walls in the oedematous tissue (Pullinger and Florey, 1935). Thus even though the surrounding tissue-pressure is higher than the intralymphatic pressure, these vessels are dilated. This chronically distended state could lead to lymphatic incompetence, and McMaster demonstrated retrograde flow in the lymphatics of some patients with chronic cardiac oedema. It is of interest to compare this finding with some of Kinmonth's radiological findings of lymphatic varicosity and dermal backflow. Secondary damage to lymphatics of an inflammatory and scarring nature in thrombophlebitis was the mechanism suggested by Hcmans (1932) to explain phlegmasia alba dolens. In our patients, however, there was no clinical evidence of inflammatory lesions. Lymphatics dilated as a result of venous obstruction have been shown to fibrose subsequently, in which case it would be difficult to differentiate these appearances from those of hypoplasia.

Finally, it is possible that a raised venous pressure could inhibit the reabsorption of lymph. Clearly a locally raised venous pressure, such as we have demonstrated, will not impede the progress of lymph which finally enters the thoracic duct, but it is possible that some lymph enters the venous system at a more peripheral site. The number of lymphatic vessels entering a lymph node commonly exceeds the number leaving it, and although Patterson, Ballard, Wasserman, and Mayerson (1958) demonstrated that there was no significant transfer of iodinated albumin from lymphatics to systemic circulation other than by the thoracic duct, the possible importance of such a transfer occurring in patients with defective lymphatic drainage has not been excluded. Bron, Baum, and Abrams (1963) demonstrated one possible direct communication between lymphatic nodes and peripheral veins in the presence of efferent-lymphatic-vessel obstruction, and we (Pentecost, Calnan, and Davies, 1964) have demonstrated substantial shunts of protein from lymphatic to venous system peripherally when the thoracic duct pressure is raised. Any such lymphatic venous transfer of fluid or protein would be opposed by a high venous pressure.

That lymphoedema praecox is due to primary lymphatic disease depends upon the demonstration by Kinmonth et al. (1957) of markedly abnormal vessels in this condition, and on the experimental work of Homans, Drinker, and Field (1934), who described the production of lymphoedema following the intralymphatic injection of silica. We have performed six radiological lymphangiograms among the patients with good evidence of venous obstruction, three of which showed normal vessels and three hypoplastic vessels. In a further patient (Case 18 ), in whom there was considerable oedema of the left leg, the lymphangiogram was normal, as was the venogram and flow studies in the supine position; there was no pressure gradient between the left common iliac vein and vena cava in this posture, but slight extension of the lumbo-sacral spine produced one of $5 \mathrm{~mm}$. Hg. In the horizontal position at rest $5 \mathrm{~mm}$. Hg represents a considerable pressure gradient in the venous system. Radiological studies were not repeated in this posture, but in view of our experience in other cases there was probably then a demonstrable venous obstruction. Thus chronic oedema which is indistinguishable clinically from lymphoedema may exist in the presence of apparently normal lymphatic vessels.

It appears to be a reasonable hypothesis to suppose that an increase in venous pressure may unmask a previously latent state of lymphatic inadequacy. If the rise in venous pressure is brought about as suggested above, this will account for the time of onset and its frequent occurrence among women. Alternatively, some of the previously described lymphangiographic appearances may be the result rather than the cause of the prolonged oedema; secondary lymphatic vessel disorder may then potentiate the oedematous state and ensure its permanence. Some of our patients have had their lymphoedema for a fairly short period, and their currently normal lymphangiograms should be repeated in the future.

This paper describes a cause of venous obstruction in the left leg only, and, although lymphoedema is frequently unilateral initially, we do not know how often this occurs on the left. In order to assess the importance of a raised venous pressure in lymphoedema which is right-sided or bilateral, it would be necessary to make a study of venous pressure in the legs of these patients while supine and standing and to compare it with a group of controls. An overriding difficulty to such a study is 
that one is probably dealing with a changing situation and that the absence of venous abnormalities at any time in the natural history of the disease does not imply their absence throughout its development.

\section{Summary}

In 23 patients with clinical primary lymphoedema starting in youth (lymphoedema praecox) the venous drainage of the affected leg has been investigated by venography and by venousflow and venous-pressure studies. Eleven of the patients showed evidence of obstruction of the left common iliac vein, probably by the right common iliac artery. Lymphangiography was performed in 10 cases, and clinical lymphoedema was seen with both abnormal and normal lymphangiographic appearances.

The manner in which a raised venous pressure could influence the onset of lymphoedema is discussed.

It is a pleasure to acknowledge the technical assistance of Mrs. Simmonds, Mr. P. Burgess, and Sister Child. The work was financed in part by a grant to one of us (J. C.) from the Wellcome Foundation.

\section{REFERENCES}

Aird, I. (1950). Proc. roy. Soc. Med., 43, 1052.

Allen, E. V. (1934). Arch. intern. Med., 54, 606. Barker, N. W., and Hines, E. A. (1946). Peripheral Vascular
Diseases. Saunders, Philadelphia and London.
Boyd, A. M. (1950). Proc. roy. Soc. Med., 43, 1045.

Bron, K. M., Baum, S., and Abrams, H. L. (1963). Radiology, 80, 194

Ehrich, W. E., and Krumbhaar, E. B. (1943). Amer. Heart 7., 26, 737.

Fraser, J. E. (1940). The Anatomy of the Human Skeleton, 4th ed. Churchill, London.

Gough, M. H., Guiney, E. J., and Kinmonth, J. B. (1963). Brit. med. f., 1, 1181 .

Homans, J. (1932). Amer. Heart F., 7, 415.

Drinker, C. K., and Field, M.'E.'(1934). Ann. Surg., 100, 812.

Kinmonth, J. B. (1952). Clin. Sci., 11, 13.

(1954). Ann. roy. Coll. Surg. Engl., 15, 1901.

- Taylor, G. W., and Harper, R. K. (1955). Brit. med. F., 1, 940. Tracey, G. D., and Marsh, J. D. (1957). Brit. $\mathscr{f}$. Surg., 45,

McMaster, P. D. (1937a). 7. exp. Med., 65, 373.

(1937b). Ibid., 65, 347.

McMurrich, J. P. (1908). Amer. F. med. Sci., 135, 342.

Milroy, W. F. (1892). N.Y. med. $\dot{f} ., 56,505$.

Nonne. M. (1891). Virchows Arch. Path. Anat., 125, 189.

Patterson, R. M., Ballard, C. L., Wasserman, K., and Mayerson, H. S. (1958). Amer. F. Physiol., 194, 120.

Peck, M. E. (1957). Ann. Surg., 146, 619.

Pentecost, B. L., Calnan, J., and Davies, A. (1964). Unpublished data.

Pullinger, B. D., and Florey, H. W. (1935). Brit. f. exp. Path., 16, 49.

Schauble, J. F., Stickel, D. L., and Anlyan, W. G. (1962). Arch. Surg., 84, 17 .

Schirger, A., Harrison, E. G., and Janes, J. M. (1962). F. Amer, med. Ass., 182, 14.

Schmorl, G., and Junghanns, H. (1959). The Human Spine in Health and Disease, translated and edited by S. P. Wilk and L. S. Goin. Heinemann, London.

Shillingford, J., Bruce, T., and Gabe, I. (1962), Brit. Heart 7., 24, 157.

Smith, R. D., Spittell, J. A., and Schirger, A. (1963). f. Amer. med. Ass., 185, 80 .

Starling, E. H. (1894). f. Physiol. (Lond.), 16, 224.

White. T. C.. Field, M. E., and Drinker, C. K. (1933). Amer. F. Physiol., 103, 343.

Zimmermann, L. M, and de Takats, G. (1931). Arch. Surg., 23, 937.

\title{
Some Experiences in Managing Sickle-cell Anaemia in Children and Young Adults, Using Alkalis and Magnesium
}

\author{
K. HUGH-JONES,* M.D., M.R.C.P. ; H. LEHMANN,† M.D., SC.D., F.R.C.P., F.R.I.C. \\ JOAN M. MCALISTER, $\ddagger$ M.SC.
}

Brit. med. F., 1964, 2, 226-229

Sickle-cell anaemia is due to an inherited defect in haemoglobin synthesis. The solubility of sickle-cell haemoglobin is lowered in the deoxygenated state. As the haemoglobin comes out of solution it forms spindle-shaped tactoids-the basis of the sickling phenomenon. Although the oxygen tension may become low enough in most tissues to induce a significant amount of sickling, this is not a constantly recurring process because, as Allison (1956) demonstrated, it requires time for deoxygenation to produce sickling, so that usually the circulating cells have become reoxygenated before this has occurred. Sickling is enhanced by acid $p H$. When the red blood cells become sickle-shaped the viscosity of the blood is increased and so the blood flow, especially in small vessels, diminishes (Harris, Brewster, Ham, and Castle, 1956). This effect, which in due course will lead to sludging, causes further deoxygenation of the blood and fall in $\mathrm{pH}$, and so a vicious circle begins which ends in actual intravascular clotting of the blood. This is the cause of most of the symptomatology of the disease.

* Chief Assistant, Children's Department, St. Bartholomew's Hospital,

London.
t Reader in Chemical Pathology, Honorary Director M.R.C. Abnormal Haemoglobin Research Unit, St. Bartholomew's Hospital, London. Now University Biochemist, Addenbrooke's Hospital, and Honorary Director M.R.C. Unit, University Department of Biochemistry, Cambridge.

$\ddagger$ Principal Physicist, St. Bartholomew’s Hospital, London.
It is not possible to alter the fundamental metabolic defect that gives rise to this abnormal haemoglobin, but what has been attempted is to try to interfere with the blood-clotting processes to make infarction less likely and to try to prevent acidosis and so to minimize intravascular sickling and sludging.

In attempting to interfere with the blood-clotting processes, something had to be found that would be economical on a large scale and not require constant supervision as do coumarin compounds. From earlier work it was known that magnesium would compete with available calcium and delay blood-clotting in vitro (Greville and Lehmann, 1944), and these observations were extended by work in vivo which showed that bloodclotting processes could be delayed and that this could be measured as a prolongation of the thrombin-generation time (Anstall, Huntsman, Lehmann, Hayward, and Weitzman, 1959 ; Huntsman, Hurn, and Lehmann, 1960). This treatment was often begun with intravenous magnesium sulphate because it had the further advantage of causing vasodilatation. This seemed to improve blood-flow where sludging was occurring and so dramatically relieve ischaemic pain. To minimize the effects of acidosis alkalis were given; sodium bicarbonate seemed the most suitable.

The following case reports show how these lines of treatment were evolved. 